\title{
The Value of Beauty in Theory Pursuit: Kuhn, Duhem, and Decision Theory
}

\author{
Gregory J. Morgan \\ College of Arts and Letters, Stevens Institute of Technology, Hoboken, USA \\ Email: gmorgan@stevens.edu
}

Received November $12^{\text {th }}, 2012$; revised December $15^{\text {th }}, 2012$; accepted December $31^{\text {st }}, 2012$

\begin{abstract}
Should judgments of beauty play a guiding role in theoretical science even if beauty is not a sign of truth? In this paper I argue that they should in certain cases. If we analyze the rationality of theoretical pursuit using decision theory, a theory's beauty can influence the utilities of the various options confronting the researcher. After considering the views of Pierre Duhem and Thomas Kuhn on aesthetics in science, I suggest that because we value freedom of inquiry we rightly allow scientists some choice in how they value aesthetic properties of theories and thus some freedom to use beauty to guide their research program.
\end{abstract}

Keywords: Beauty; Aesthetics in Science; Decision Theory; Pierre Duhem; Thomas Kuhn; Logic of Pursuit; Aesthetic Value; Freedom of Inquiry

\section{Introduction}

What is the proper role of beauty in theoretical science? Those I call aesthetes claim that judgments of beauty can be a guide to the truth. For example, the philosopher of science James McAllister argues that because of the way the meaning of beauty changes over time, there is good reason to think that beauty is a sign of truth (McAllister, 1996, 1998). The physicist Brian Greene describes how theoretical physicists often use the elegance and beauty of theories as "a powerful and insightful guide" when empirical evidence is difficult to muster (Greene, 1999 , p. 167). Others, including me, are skeptical of McAllister's claims and the reasonableness of Greene's optimism (Morgan, 2005). If McAllister is wrong and beauty is not a sign correlated with truth, is it possible that beauty plays a nonepistemic role in science? Are there other functions for beauty or judgments of beauty in theoretical science? Here is another area in which the aesthetes and their opponents can debate (Wechsler, 1978; Curtin, 1980; Tauber, 1997).

One way to approach this question is through the notion of value. Does beauty have value in science? If so, is beauty one of science's fundamental values or does beauty derive its value from its relation to other values? Can we compare the different types of value - aesthetic, epistemic, pragmatic, economic etc.operative in science? Is there an objective ordering of values in terms of importance or is the relative importance of the different types of value essentially contextual? I will argue that decision theory allows one to begin to answer some of these questions.

A second way to approach the question of the role of beauty in theoretical science is to consider its relevance to action in science. In particular, should the beauty of a theory influence how a scientist acts regarding the theory? For example, instead of claiming that its beauty gives us a reason to believe a beautiful theory, as we might if beauty were a sign of truth, the aesthete might claim that the beauty of a theory gives a reason to pursue the theory. In other words, the beauty of a theory might provide a reason to work out the consequences of the theory, apply it to more complex systems, add or reformulate its assumptions, or, in general, devote time and money to developing the theory and its potential evidence, etc., even if the beauty of the theory is not a reason to believe it. A consideration of reasons for pursuit is said to be a consideration of the "logic of pursuit" in contrast to the better-known "logic of justification" (Curd, 1980; Achinstein, 1993). I will argue that beauty can play a significant role in the logic of pursuit.

In this paper, I will briefly analyze the views of two influential thinkers on the role of beauty in science: Pierre Duhem and Thomas Kuhn. Following the survey, I will recast their positions within decision theory, a framework in which the logic of pursuit can be made more precise and the role and value of beauty in theoretical science can be better understood. In each case, beauty is related to the utility of pursuing a theory, although in different ways. Finally, I will propose that the value of beauty in science is related to freedom of scientific inquiry.

\section{Pierre Duhem: Beauty Is a Fundamental Value of Science}

Pierre Duhem, in his influential The Aim and Structure of Physical Theory, has been widely discussed as promoting antirealism: the view that science does not, and should not, aim to discover truths about reality (see for example, Musgrave, 1999). However, Duhem's position is subtler than usually thought. He thinks that physical theory "represents," as simply, completely, and exactly as possible, a set of experimental laws and that it is impossible not to think that the resulting "natural classification" of experimental laws corresponds to "real affinities among the things themselves" (Duhem, 1954: pp. 19-26). Nonetheless, he argues the representation of experimental laws neither explains reality nor "conforms" to it. Furthermore, in a spirit reminiscent of David Hume, Duhem claims that we cannot prove that nature possesses the real affinities suggested by the relations in the classification although we cannot help but think such connections 
exist. Thus, he does not think that the aim of theoretical science is to reveal truth in any realist sense, although the structure of physical theory may "hint" at the real affinities of things (Duhem, 1954: p. 30). Rather, he suggests that the fundamental value of theoretical science is a beautiful orderly classification and an economical representation of otherwise disparate experimentally discovered physical laws:

Order wherever it reigns, brings beauty with it. Theory not only renders the group of physical laws it represents easier to handle, more convenient, and more useful, but also more beautiful.

It is impossible to follow the march of one of the great theories of physics, to see it unroll majestically its regular deductions starting from initial hypotheses, to see its consequences represent a multitude of experimental laws down to the small detail, without being charmed by the beauty of such a construction, without feeling keenly that such a creation of the human mind is truly a work of art (Duhem, 1954: p. 24).

For Duhem, the orderly representation and classification that is theoretical physics is beautiful.

We must make some interpretative moves before we can claim that Duhem thinks that creation of beautiful theories is a fundamental value of science, however. To see this point, consider two senses of value of science. In the first sense, if $X$ is a value of science and $\mathrm{Y}$ is coextensive with $\mathrm{X}$ then $\mathrm{Y}$ is also a value of science. In the second sense of value, if $X$ is a value of science and $\mathrm{X}$ is co-extensive with $\mathrm{Y}$, it does not follow that the value of science is also Y. Which of these two senses is more plausible for Duhem's conception of beauty? If Duhem thought that there was only a contingent connection between order and beauty, then one could argue that Duhem's notion of the aim of theoretical science is not to reveal beauty, necessarily, but to articulate order. Nonetheless, it is more plausible that Duhem took the connection between beauty and order in theoretical science to be necessary. For example, one could argue that for Duhem, theoretical beauty just is theoretical order. Thus on a plausible reading of Duhem, he claims that a beautiful physical theory realizes a fundamental value of science to a greater extent than an ugly alternative.

\section{Thomas Kuhn: Beauty as Subjective Value}

In his Structure of Scientific Revolutions, Kuhn claims that "aesthetic considerations" can lead scientists to reject an old paradigm in favor of a new one (Kuhn, 1970: p. 155). He says little about what he means by "aesthetic considerations," but in his postscript, he gestures at judgments of simplicity, consistency, and plausibility (Kuhn, 1970: p. 185). In a later article, Kuhn considers aesthetics in science more directly. On the relation between art and science, Kuhn writes:

Undoubtedly, ... considerations of symmetry, of simplicity and elegance in symbolic expression, and other forms of the mathematical aesthetic play important roles in [art and science]. But in the arts, the aesthetic is itself the goal of the work. In the sciences it is, at best, ... a tool: a criterion of choice between theories that are in other respects comparable, or a guide to the imagination seeking a key to the solution of an intractable puzzle (Kuhn, 1969: p. 342).

Although Kuhn probably would not have put it this way, the quotation suggests two roles for aesthetics in science: one in the context of justification and another in the context of discovery. Additionally, as Margolis argues, it seems overly restrictive to confine these two roles to revolutionary science as Kuhn does (Margolis, 1997: p. 193). It is the former role in theory choice that is pertinent to our current discussion-how aesthetic considerations supposedly guide us to adopt one theory over another. Kuhn's notion of theory adoption or theory "choice" is ambiguous. It can be interpreted to mean adopt-as-true or to mean adopt-as-worthy-of-pursuit. Kuhn is usually interpreted as intending the latter.

For Kuhn, some properties responsible for a theory's beauty are the same properties of theories or "theoretical values" that feature in standard lists of criteria for theory choice. Kuhn himself mentions five criteria for "evaluating the adequacy of a theory": accuracy, consistency, scope, simplicity, and fruitfulness (Kuhn, 1973: p. 323). He acknowledges that the list is incomplete and that there are differences in how we interpret each one as well as further difficulties in assigning relative weights to each criterion. Presumably, we could add further criteria such as consilience, explanatory power, elegance, computational tractability, visualizibility, etc., as well as more specific properties of theories. Not surprisingly, there is not universal agreement over which, if any, of these criteria for theory choice are aesthetic. Further, even if a theory is beautiful because of its simplicity say, it does not follow that all cases of simplicity are aesthetic. Nonetheless, Kuhn's remarks suggest that he thinks at least some of these criteria are aesthetic, and additionally, that the particular balance between them can be an aesthetic choice.

For Kuhn, members of a scientific community share, among other things, a common set of values. Some of these values are aesthetic. For example, a specific interpretation of the meaning of simplicity might involve an appeal to what is beautiful. Suppose that a scientist accepts one theory $\mathrm{T}_{\mathrm{B}}$ over a competing $T_{U}$ because $T_{B}$ is more beautiful than $T_{U}$. It does not follow that she believes $\mathrm{T}_{\mathrm{B}}$, since for Kuhn, theory acceptance need not involve belief. Rather it is a commitment to the theory that is based on values that define the scientist as being a member of a particular scientific community. Now one might worry that the values within scientific communities are not objective but change over time and from person to person. Kuhn is receptive to this possibility:

... values may be shared by men who differ in their application. Judgments of accuracy are relatively, though not entirely, stable from one time to another and from one member to another in a particular group. But judgments of simplicity, consistency, plausibility, and so on often vary greatly from individual to individual (Kuhn, 1970: p. 187).

Aesthetic values are more likely to be of the latter more variable type of value and thus a pernicious subjectivism looms. Kuhn replies to this potential problem with the following two points:

First, shared values can be important determinants of group behavior even though the members of the group do not apply them in the same way... Men did not paint alike during the periods where representation was a primary value, but the developmental pattern of the plastic arts changed drastically when that value was abandoned... Second, individual variability in the application of shared values may serve essential functions in science... If all the members of a community responded to an anomaly as a source of crisis or embraced each new theory advanced by a colleague, science would cease (Kuhn, 1970: p. 188).

Kuhn's response to the problem of subjectivity invites many 
more questions. What determines the limits of the variation in value application? Would science really cease if there were perfect agreement on the interpretation and application of values? Surely there could be disagreement over how to interpret the theories themselves (as opposed to merely disagreement over the criteria of choice). In addition to intra-community variation in values, there can be inter-community variation. Members of different paradigms may share wildly different conceptions of beauty. This is one reason that Kuhn does not talk in terms of "reasons for belief" when discussing theory choice since it is possible for scientists from different paradigms to adopt or choose different theories given the same evidence based on the same values but differentially interpreted and/or weighted. Indeed it is possible on Kuhn's view that for any two theories of a given phenomena, $T_{1}$ and $T_{2}$, if scientist $S_{1}$ from paradigm 1 adopts $T_{1}$ over $T_{2}$, then scientist $S_{2}$ from paradigm 2 adopts $T_{2}$ over $T_{1}$. For many philosophers who desire a more robust sense of objectivity, this result renders Kuhn's position overly liberal. Nonetheless, Kuhn does illustrate how aesthetic value might play a role in theory acceptance, even if beauty is not a sign of truth and he takes seriously the variation in how aesthetic properties are weighted.

\section{A Decision-Theoretic Analysis}

Decision theory allows one to analyze the role of beauty in the logic of pursuit. I will develop an idea of Hempel (1965), who suggests we quantify the utility of the possible outcomes of research and treat theory acceptance as a question of decision theory. With this analysis in place, the relations among the thinkers will be clearer.

The overarching normative principle of decision theory is that one should act in such a way as to maximize expected utility of the action. To see how this principle is applied to the question of the practical relevance of beauty, consider a case where we are considering pursuit with respect to two mutually exclusive theories, one beautiful $\mathrm{T}_{\mathrm{B}}$ and one ugly $\mathrm{T}_{\mathrm{U}}$. To keep the analysis relatively simple, let us assume that for each theory one has to choose simply to pursue it or not ${ }^{1}$. (A more general analysis might consider deciding the degree $r_{i}$ to pursue each theory $\mathrm{T}_{\mathrm{i}}$ ). The relevant magnitudes can be summarized in Table 1. There is no column for both $T_{B}$ and $T_{U}$ being true in Table 1 since we assumed that the two theories were mutually exclusive. The probabilities sum to unity: $\mathrm{P}\left(\mathrm{T}_{\mathrm{B}}\right)+\mathrm{P}\left(\mathrm{T}_{\mathrm{U}}\right)+$ $\mathrm{P}\left(\sim \mathrm{T}_{\mathrm{U}} \& \sim \mathrm{T}_{\mathrm{B}}\right)=1$. The expected utility of an action is calculated by summing the utilities weighted by the probability that the appropriate state of affairs obtains.

The expected value of pursuing $T_{B}$ (and not pursuing $T_{U}$ ) consists of three terms:

$$
\begin{aligned}
& \text { E (Pursue } T_{B} \text { only) } \\
& =P\left(T_{B}\right) U\left(\text { Pursue } T_{B} \text { only } / T_{B}\right) \\
& +P\left(T_{U}\right) U\left(\text { Pursue } T_{B} \text { only } / T_{U}\right) \\
& +P\left(\sim T_{U} \& \sim T_{B}\right) U\left(\text { Pursue } T_{B} \text { only } / \sim T_{U} \& \sim T_{B}\right)
\end{aligned}
$$

${ }^{1}$ Rota (1997) makes the point that, in mathematics at least, one does not directly pursue beauty if one hopes to create it. If such a view were correct of all of empirical science, it would undermine the goal of this paper. I assume that the choice is between pursuing two theories that have been partially developed such that we can determine that one is beautiful and one is not.

\begin{tabular}{|c|c|c|c|}
\hline & $\begin{array}{c}T_{B} \text { is true } \\
P\left(T_{B}\right)\end{array}$ & $\begin{array}{c}\mathrm{T}_{\mathrm{U}} \text { is true } \\
\mathrm{P}\left(\mathrm{T}_{\mathrm{U}}\right)\end{array}$ & $\begin{array}{l}\text { Both are false } \\
\mathrm{P}\left(\sim \mathrm{T}_{\mathrm{U}} \& \sim \mathrm{T}_{\mathrm{B}}\right)\end{array}$ \\
\hline $\begin{array}{l}\text { Pursue } \\
\mathrm{T}_{\mathrm{B}} \text { only }\end{array}$ & $\mathrm{U}\left(\right.$ Pursue $\mathrm{T}_{\mathrm{B}}$ only/ $\mathrm{T}_{\mathrm{B}}$ ) & $\mathrm{U}\left(\right.$ Pursue $\mathrm{T}_{\mathrm{B}}$ only/ $\left.\mathrm{T}_{\mathrm{U}}\right)$ & $\begin{array}{c}\mathrm{U}\left(\text { Pursue } \mathrm{T}_{\mathrm{B}} \text { only }\right. \\
\left.\quad / \sim \mathrm{T}_{\mathrm{U}} \& \sim \mathrm{T}_{\mathrm{B}}\right)\end{array}$ \\
\hline $\begin{array}{l}\text { Pursue } \\
\mathrm{T}_{\mathrm{U}} \text { only }\end{array}$ & $\mathrm{U}\left(\right.$ Pursue $\mathrm{T}_{\mathrm{U}}$ only/ $\left.\mathrm{T}_{\mathrm{B}}\right)$ & $\mathrm{U}\left(\right.$ Pursue $\mathrm{T}_{\mathrm{U}}$ only/ $\mathrm{T}_{\mathrm{U}}$ ) & $\begin{array}{l}\mathrm{U}\left(\text { Pursue } \mathrm{T}_{\mathrm{U}} \text { only }\right. \\
\left.\quad / \sim \mathrm{T}_{\mathrm{U}} \& \sim \mathrm{T}_{\mathrm{B}}\right)\end{array}$ \\
\hline $\begin{array}{l}\text { Pursue } \\
\text { neither }\end{array}$ & $\mathrm{U}\left(\right.$ Pursue neither $\left./ \mathrm{T}_{\mathrm{B}}\right)$ & $\mathrm{U}\left(\right.$ Pursue neither/ $\left.\mathrm{T}_{\mathrm{U}}\right)$ & $\begin{array}{l}\text { U(Pursue neither } \\
\left.\quad / \sim \mathrm{T}_{\mathrm{U}} \& \sim \mathrm{T}_{\mathrm{B}}\right)\end{array}$ \\
\hline $\begin{array}{l}\text { Pursue } \\
\text { both }\end{array}$ & $\mathrm{U}\left(\right.$ Pursue both/ $\left.\mathrm{T}_{\mathrm{B}}\right)$ & $\mathrm{U}\left(\right.$ Pursue both/ $\left.\mathrm{T}_{\mathrm{U}}\right)$ & $\begin{array}{l}\text { U(Pursue both } \\
\left./ \sim \mathrm{T}_{\mathrm{U}} \& \sim \mathrm{T}_{\mathrm{B}}\right)\end{array}$ \\
\hline
\end{tabular}

Table 1.

A decision theoretic matrix for theory pursuit. $U(X / Y)$ symbolizes the utility of doing $\mathrm{X}$ given $\mathrm{Y}$ is true.

Analogous equations hold for the three other possible actions. The most reasonable course of action has the highest expected utility. A more reasonable course of action has a greater expected utility than a less reasonable course of action. To calculate the maximal expected utility and hence the most reasonable course of action, one needs more information than merely the probabilities that are used in determining what to believe. In theory, one calculates the expected utilities of all the possible actions (i.e., the four actions above in our case) and the action with the highest expected utility is the most reasonable one. Decision theory shows a way in which beauty can be relevant to how scientists should act toward theories, even if it is irrelevant to the probabilities of theories. If beauty influences the values of the utilities, it can influence the most reasonable course of action.

The use of the decision-theoretic framework to illuminate the role of aesthetics relies on a number of contestable assumptions. Perhaps the most significantly, decision theory assumes that the expected net benefit, a single number, can adequately represent the net value of an action. Pursuing a theory might create different types of value - producing knowledge, making predictions, creating a beautiful object, making possible technical progress, etc.- and decision theory assumes that these different types of value can somehow be summed. An opponent of this approach might argue that different sorts of value cannot be summed in this way. He or she could argue that the different sorts of value are incommensurable and that there exists no one-dimensional measure that captures a "total" amount of value or utility. In response, let me make three points. First, we often do place a single numerical value on beautiful things, for example, in art auctions. Second, when using decision theory, we often do not need to assign definite numbers to the utility values in order to work out the most reasonable course of action. Under certain conditions, just the relative differences in utility are sufficient to determine which course of action is most reasonable. Finally, when we choose to act one way rather than another, we have, in effect, assigned relative weights to conflicting values. Although we might not be conscious of using any rules to make the choice, this unawareness does not mean that the action cannot be accurately described as following inter-value balancing principles.

\section{Two Decisions: By the Society and by the Individual}

The question of inter-value balance is a difficult one. I suggest that to make some progress we separate at least two dis- 
tinct projects that so far have been conflated. First we can consider the above matrix as representing the decision parameters of a single scientist considering which theory to pursue. Second, we can consider the above matrix as representing the decision parameters of a larger group of people, and at the extreme, society as a whole. When issues of how society should fund research are used to justify study of "the logic of pursuit," these two distinct projects risk being conflated. At the national level, funding agencies make these decisions on behalf of the society. The utility values for a single scientist and for society need not be the same. In fact, we would expect them to differ because we would expect different types of outcomes of theoretical pursuit to be relevant to different degrees and therefore the utilities for society and the individual scientist to be different. Of course, this does not mean that many of the consequences valued by the scientist will not be valued by society too. For example, we would expect that the aesthetic pleasure that a scientist gains by pursuing a theory to be weighted more highly by the individual scientist pursuing the theory than by society at large. On the other hand, contemplation of the beautiful theories of science could be argued to be a social good that funding agencies should take into consideration. Nonetheless, it would be an unlikely coincidence if the degree of value attributed to pursuit of a beautiful theory were the same for the person pursuing the theory and society at large.

\section{Inter-Value Realism and Inter-Value Antirealism}

On either the individualistic or the social project, the crux of the decision theoretic rendition turns on the relative amounts of the relevant utilities. Philosophers might be grouped into two groups according to how they approach this problem. First, there are the inter-value realists. They hold that the correct balance among different types of values is independent of what we take the balance to be. In other words, there is a correct balance to be discovered and whatever this balance is, it does not change if we change what we take it to be. Opposed to the inter-value realists are the inter-value anti-realists. They hold that the correct balance among different types of value depends, at least in part, on what we take them to be. They would argue that the facts needed to justify the realists' balance do not exist. For them, there is no correct balance to be discovered; rather it has to be invented by us. The distinction between inter-value realists and anti-realists is vague insofar as the referent of "we" in the above distinction is vague. To be more precise, let "we" refer to the individual scientist in question in the individual decision problem and refer to society in the societal decision problem. Notice that it is not inconsistent to be a realist with respect to one of these decision problems and not with the other. The instrumental rationality that is usually assumed by decision theorists is neutral on the inter-value realism/antirealism issue. Stripped down decision theory does not provide any constraints on the utility values, nor a way to determine them. Rather fundamental values in the form of utilities are taken as given, and action is judged reasonable relative to the utilities. This is true of both the individual and the social decision problems.

\section{Duhem, Kuhn, and Decision Theory}

Keeping in mind the decision theoretic approach, the distinction between an individualistic and societal perspective, and the distinction between a realist and an anti-realist view of utilities, let us return to the views of Duhem and Kuhn. Can their views be captured within decision theory? Can we categorize them neatly with the distinctions I have drawn?

Let us begin with Duhem. He thinks that beauty accompanies the order that scientists should aim for in constructing their theories. His view is that order is a fundamental value of theoretical science does not depend upon what we take the fundamental values of science to be. Neither do the utilities associated with pursuing a given theory. Duhem, then, on my account, is an inter-value realist. In fact, he is an inter-value realist at both the individual and the societal levels. His position is most apparent when he discusses the imaginative yet shallow "weakminded" English scientist. He chastises English scientists, notably Sir William Thomson and James Clerk Maxwell, for providing a series of disconnected models rather than an ordered theoretical science. He clearly thinks that if a scientist had to choose between pursuing an abstract beautiful "French" theory and a shallow ugly "English" one, she should pursue the French one. This truth is independent of whether we take the utility of the English type of theory to be superior, as the English scientists he mentions did. In other words, Duhem thinks that the English scientists are wrong to think that their way of doing things is better. Science as a whole, and individual scientists in particular should emulate the French scientist. To put Duhem's position in the language of decision theory, he thinks that $\mathrm{E}$ (pursuing $\mathrm{T}_{\mathrm{B}}$ only) $>\mathrm{E}$ (pursuing $\mathrm{T}_{\mathrm{U}}$ only) in large part because TU does not possess the order that characterizes good theories. Can we attribute to Duhem views about the utility values we find in the decision matrix? This attribution is made difficult because the various values are predicated on different truth-values of TB and Tu. As mentioned above, standardly interpreted, Duhem does not believe that theories are true or false, in the sense that they correspond with the world. Let us assume that where we consider the probability of a particular theory, Duhem understands it to mean the probability of the theory containing "natural affinities," to use his language. Duhem, I claim, would argue that it is impossible for a theory without order to show "natural affinities." If this is so, then the utility associated with the pursuit of a true ugly theory is irrelevant to practical reason, i.e., $\mathrm{U}\left(\right.$ Pursue $\mathrm{T}_{\mathrm{U}}$ only/ $\mathrm{T}_{\mathrm{U}}$ ) multiplied by $0=0$. Indeed, at root Duhem's desire to pursue theories with order and beauty seems to be driven by a metaphysical belief that the world has "ontological order" and that this order can only be captured by an orderly physical theory; thus $\mathrm{p}\left(\mathrm{T}_{\mathrm{B}}\right)>$ $\mathrm{p}\left(\mathrm{T}_{\mathrm{U}}\right)$. Duhem is quite conservative in this regard.

Nonetheless, if we assume that $\mathrm{p}\left(\mathrm{T}_{\mathrm{U}}\right)>0$, and if decision theory can be applied to Duhem's position, then we need values of pursuit given that $T_{U}$ is true. Duhem does consider whether the ugly English models are fruitful for discoveries (Duhem, 1954: p. 93). After a brief historical survey, he concludes that, "the share of the booty it [the use of ugly mechanic cal models] has poured into the bulk of our knowledge seems quite meager when we compare it with the opulent conquests of the [French-style] abstract theories" (Duhem, 1954: p. 99). In fact, although there have been some discoveries with the use of models, their use of these models may even "obscure discoveries already made." Furthermore, the beautiful abstract theory has the extra utility of being an orderly classification and the extra utility due to the "esthetic emotion" that it produces (Duhem, 1954: p. 24). In the language of decision theory, Duhem claims $\mathrm{U}\left(\right.$ Pursue $\mathrm{T}_{\mathrm{B}}$ only) $\gg \mathrm{U}\left(\right.$ Pursue $\mathrm{T}_{\mathrm{U}}$ only) and perhaps even 
U(Pursue $\mathrm{T}_{\mathrm{B}}$ only $\left./ \mathrm{T}_{\mathrm{U}}\right)>\mathrm{U}\left(\right.$ Pursue $\mathrm{T}_{\mathrm{U}}$ only $\left./ \mathrm{T}_{\mathrm{U}}\right)$.

Relative to Duhem, Kuhn is a radical. He is an inter-value anti-realist, at both the individual and societal levels. He argues that the balance between different values varies across time and among scientists. This variation in values promotes efficient science, since diversity and competition between different perspectives drives science forward, or so Kuhn argues. How an individual scientist (correctly) balances the different types of value is in part dependent on the importance that scientist places on the values. Kuhn argues that "features of individual personality and biography" explain much of the variation among scientists (Kuhn, 1970: p. 185). The scientist is constrained to some degree by her "professional initiation" into a paradigm: to remain within her paradigm, her balance cannot vary significantly from the paradigm average, but nonetheless, there can be personal differences among different members of the same paradigm. At the societal level, Kuhn does not attribute science as a whole with fundamental values beyond the values that all scientists share. Presumably these values are quite weak as any interesting value has associated with it disagreement that fractures the scientific community into more specific scientific communities. Kuhn does, however, think that paradigms are constituted by largely shared values. The particular balance and interpretation of the values constituting a paradigm are not determined top-down, but rather emerge as a rough consensus among member scientists. Kuhn's position can be captured within decision theory very well. Each scientist's set of values applied to a particular decision is represented by a set of utility values and the paradigm values can be represented by the mean and standard deviation of the population. Typically we would expect members from a single paradigm to largely agree over which theory should be pursued.

Kuhn can accommodate the example of the anti-aesthete within his framework. In fact, there is nothing within his system that prohibits a community of anti-aesthetes constituting a paradigm. Some may argue that this is a weakness of his system - that it is too loose to rule out cases such as this. Indeed, in his 1970 postscript, Kuhn adamantly defends his position from charges of irrationality made by Lakatos and others. A charge of irrationality would be valid if scientists could give up a value like consistency, perhaps, but here we are discussing how to react to aesthetic features of our theories of the world. In fact, one could make the case on behalf of Kuhn that if every scientist chose to work on the beautiful theory and not the ugly alternative, that this tendency would bias scientific practice as a whole and delay us developing a true ugly theory, if in fact the world is best described by an ugly theory. That a small percentage of scientists do concern themselves with counting ladybug populations is not a bad thing.

\section{Beauty and the Freedom of Inquiry: A Proposal}

Let me end by sketching the beginnings of an inter-value anti-realist view at the individual level. As a society we allow individual scientists the freedom to formulate and prioritize their own values. There are some constraints that are often codified by legal and ethical imperatives, but generally society does not dictate methodological values to individual scientists and neither should it. Each scientist is given the freedom to choose the exact balance between different kinds of value and to use this balance to guide his or her research program. My position is clearly inter-value antirealist as the "correct" balance between values for an individual scientist is determined by what the individual scientist takes them to be. Of course, there are incentives for an individual scientist not to choose a balance too far from her community norm if she wishes to be a successful member of that scientific community. Two ways of justifying this attitude toward its scientists are open. One could argue that granting such freedom to scientists leads to efficient science, or one could argue that the value of the freedom granted is its own justification. The former type of justification lies behind Paul Feyerabend's famous crusade against fixed rules of methodology (Feyerabend, 1975; Lloyd, 1996). Although he is concerned more with the free choice or rejection of methodological rules, Feyerabend's writings also support the idea of freedom of choice of value. The latter option makes freedom of inquiry, in the sense of choice of values as well as choice of project, a fundamental value of science.

Beyond being an inter-value antirealist position, how does this view fit into the decision theoretic framework I presented earlier in this chapter? There are some difficulties in representing the value of freedom within the decision theoretic framework. On the other hand, there is synergy also. For decision theory to be useful, one has to presuppose that the decider is free to choose any of the options represented (For a related point, see Sen, 2002: p. 593). If there were no freedom, then it would be futile to calculate the most rational course of action because it could not be chosen. I am, however, proposing a more radical freedom, not the freedom to choose what theory to pursue, but rather to choose which properties of a theory are valuable and to what degree. More specifically, I suggest that individual scientists can choose the degree to which they value beautiful properties of theories. On my view, theoretical pursuit can be seen as a two-stage process: first choose the properties that you value and their relative strength; then apply these values to select the theory to pursue. The second stage is simply an application of decision theory as I have presented it earlier.

Decision theory has its limitations. If we turn our attention to how to use decision theory to decide what properties of theories to value with high utilities, we confront the possibility of an infinite regress. In other words, to use decision theory to choose which properties of theories to value, we need utility values for adopting these utility values and we merely push the problem back one level. How do we determine these 2nd order utility values? To apply decision theory requires that we have 3rd order utility values. And the infinite regress takes hold. There are additional problems applying decision theory to the choice of utility values. Consider the case where we choose between two inequalities: 1) $\mathrm{U}\left(\mathrm{T}_{\mathrm{B}} / \mathrm{X}\right)>\mathrm{U}\left(\mathrm{T}_{\mathrm{U}} / \mathrm{X}\right)$; and 2) $\mathrm{U}\left(\mathrm{T}_{\mathrm{B}} / \mathrm{X}\right) \leq$ $\mathrm{U}\left(\mathrm{T}_{\mathrm{U}} / \mathrm{X}\right)$. Applying decision theory to this problem requires that we use probabilities such as $\mathrm{p}\left[\mathrm{U}\left(\mathrm{T}_{\mathrm{B}} / \mathrm{X}\right)>\mathrm{U}\left(\mathrm{T}_{\mathrm{U}} / \mathrm{X}\right)\right]$. But what do such probability statements mean? If one is an inter-value realist, these statements mean the probability that the value of utility pursuing $T_{B}$ is greater than pursuing $T_{U}$. For the inter-value realist these probabilities are defined independently of what the individual scientist takes the utilities to be. For the inter-value antirealist, however, these probabilities are not independent of what the scientist takes the utilities to be. But what the scientist takes the values to be just is what the decision problem is trying to solve. Thus, the inter-value anti-realist encounters a circularity in determining the probability values for the above decision problem: the decision depends on the probability values, which in turn depend upon the decision.

The freedom to choose utility values cannot be entirely gov- 
erned by decision theory. There must also be what might be called the spontaneity of individual values. That a particular scientist chooses to pursue a beautiful theory over an ugly theory (because she has chosen to value beauty over ugliness) is a right that we as a society respect. No doubt that there are empirical connections between certain theoretical properties that are candidates for values and the practical outcomes that society values. These connections are exploited by funding agencies on our behalf to promote biases in research that hopefully lead to more valuable outcomes for future society. However, many of the ultimate theoretical values are fixed neither by society nor by reason, and we add to their value by allowing individual scientists to freely choose them (see Sen, 2002, Chapters 20 and 21, for more on the value of freedom of process.) A controversial consequence of my position is that it would not be irrational for an individual scientist (the antiaesthete) to pursue the uglier alternative, if her choice of values dictated this course of action. Kuhn might be right that many scientists' values are mostly fixed by their professional history and context. But scientists are not entirely passive. They have the ability to choose the value of beauty and thus how to react to it. An anti-aesthete, although rare, is not necessarily irrational.

To return to an opening question of this paper: Is beauty a fundamental value of research? Not necessarily. There is no global answer. However, locally many scientists choose it to be one of their implicit fundamental values. Ceteris paribus, they would rationally pursue a beautiful theory over an ugly rival. This is true even if beauty does not lead to any more practical benefits. For them, the value of beauty exemplifies their right to the freedom of inquiry. On the flip side of the coin, I suggested that an anti-aesthete who reverses the typical aesthetic ordering also illustrates society's willingness not to restrict the freedom of inquiry. Feyerabend argues that this pluralism is good for inquiry and society as a whole. I suggest that it also could be justified by the value of freedom of inquiry itself.

\section{Summary and Conclusion}

If beauty were irrelevant to a theory's truth or probability, would beauty be irrelevant to the practice of guiding theoretical science? No, not necessarily. Decision theory shows how aesthetic value can influence the utility of theory pursuit. For many scientists, the beauty of a theory increases the expected utility of pursuing the theory. For them, there is an important sense in which beauty is a fundamental value of their science. I argued that we should distinguish at least two different decisions: 1) the decision confronting an individual scientist over what theory to pursue; and 2) the decision confronting a society over what research to fund and promote. The role of beauty need not be the same in both cases. Duhem and Kuhn argue that aesthetic value should influence how scientific research should proceed. Their insights can largely be captured within the decision theoretic framework. Kuhn disagrees with Duhem over the status of the various utilities associated with pursuing a given beautiful theory. Duhem believes that the balance between different types of value is independent of what we take it to be. $\mathrm{He}$ is an inter-value realist. He thinks that certain aesthetic values are fixed by the nature of (correct) science. Kuhn, on the other hand, promotes the importance of individual variation and argues that the correct balance between different types of value depends upon one's personal biography. Alternatively, I suggested that one could argue that the value of freedom of inquiry justifies a scientist's right to value aesthetic properties in a manner that she sees fit, given certain constraints. On this suggestion, freedom of inquiry underwrites an inter-value anti-realism at the individual level. One consequence-and one virtue - of my view is that some scientists can reasonably choose to pursue ugly theories over otherwise similar beautiful alternatives.

\section{Acknowledgements}

I thank Peter Achinstein and Christopher Smeenk for comments on an earlier draft. Jennifer McBryan helped with stylistic suggestions.

\section{REFERENCES}

Achinstein, P. (1993). How to defend a theory without testing it: Niels bohr and the "logic of pursuit". Midwest Studies in Philosophy, 13, 90-120.

Curd, M. (1980). The logic of discovery: An analysis of three approaches. In T. Nickles (Ed.), Scientific discovery, logic, and rationality (pp. 201-219). Dordrecht: D. Reidel Publishing Company.

Curtin, D. (1980). The aesthetic dimension of science: The sixteenth nobel conference. New York: Philosophical Library.

Duhem, P. (1954). Aim and structure of physical theory. Princeton, NJ: Princeton University Press.

Feyerabend, P. (1975). Against method. London: New Left Books.

Greene, B. (1999). The elegant universe. New York: Vintage Books.

Hempel, C. (1965). Inductive inconsistencies. In C. Hempel (Ed.), Aspects of scientific explanation (pp. 53-79). New York: The Free Press.

Kuhn, T. S. (1969). Comment on the relations between science and art. In T. S. Kuhn (Ed.), The essential tension (pp. 340-351). Chicago: University of Chicago Press.

Kuhn, T. S. (1970). The structure of scientific revolutions. Chicago: University of Chicago Press.

Kuhn, T. S. (1973). Objectivity, value judgment, and theory choice. In T. S. Kuhn (Ed.), Essential tension (pp. 320-339). Chicago: Chicago University Press.

Lloyd, E. (1996). Feyerabend, mill, and pluralism. Philosophy of Science, 64, S396-S407.

Margolis, J. (1997). Objectivity: False leads from T. S. Kuhn on the role of the aesthetic in the sciences. In A. Tauber (Ed.), The elusive synthesis: Aesthetics and science (pp. 189-202). Dordrecht: Kluwer Academic Publishers.

McAllister, J. (1996). Beauty and revolution in science. Ithaca: Cornell University Press.

McAllister, J. (1998). Is beauty a sign of truth in scientific theories. American Scientist, 86, 174-183. doi:10.1511/1998.2.174

Morgan, G. J. (2005). The beauty of symmetrical design: The alleged epistemic role of beauty in theoretical science. $\mathrm{Ph} . \mathrm{D}$. Thesis, Baltimore: Johns Hopkins University.

Musgrave, A. (1999). Essays on realism and rationalism. Amsterdam: Rodopi.

Rota, G. (1997). The phenomenology of mathematical beauty. Synthese, 111, 171-182. doi:10.1023/A:1004930722234

Sen, A. (2002), Rationality and freedom. Harvard: Harvard Belknap Press.

Tauber, A. (1997). The elusive synthesis: Aesthetics and science. Dordrecht: Kluwer Academic Publishers.

Wechsler, J. (1978). On aesthetics in science. Cambridge: MIT Press. 